Edited by S F Spicker, S R Ingman and I R Lawson, 298 pages, Dordrecht, $£ 37.00$, hbk, Reidel Publishing Co, 1987

Make new friends but don't forget the old - new are silver, old are gold. This is the key message of this ethical book. Its contributors represent the disciplines of geriatric medicine, psychiatry, public health, nursing, medical sociology, political science, health law, journalism, and moral philosophy. The book is developed from a symposium entitled Geriatrics: Ethical and Economic Conflicts for the 21st Century, which was held at the University of Connecticut Health Centre in Farmington, on 20-22 September 1984. The authors do not claim that this volume encompasses all the relevant or central issues at stake.

The four sections of this book deal with: understanding the biology and epidemiology of aging; philosophical reflections on medical care provision for the aged; self-determination in late-life dependency, and justice in the provision of medical care for the aged. The epilogue is devoted to the prosthetic era of human life - the last scene of all. The text is readable, supported by figures and references, and deals with the population of the United States. Americans of 65 plus, who accounted for only four per cent of the population in 1900, represented more than 11 per cent of the US population by 1980 and this trend of aging is expected to continue well into the 21 st century. This multi-author book explores: the value conflicts likely to surround the continued aging of the US population; the health and social status of the elderly in the future; the potential of the elderly for selfdetermination in later life, and the health requirements with regards to limited (or unlimited) national resources. It is a serious book but makes good armchair reading.

In their contributions Molly Gavin, Gayle Kataja, Nancy Dubler, and Margaret Battin explore health care decision-making with four critical questions in mind: how should such decisions be made? Who should make such decisions? What range of options should be available? And when (and on what basis) should these decisions be subject to third-party control or review? They consider how the elderly, especially the dependent elderly, fare in our society. They plead for balance and fairness in caring for the elderly. A desirable public policy, in their opinion, must include three key elements: firstly, a realistic understanding of aging and of the perspective of the elderly person; secondly, a candid assessment of the criteria and procedures for societal intervention in the lives of the dependent elderly, and thirdly, an honest acknowledgement of our ability and.willingness to provide resources for the care of the elderly.

One chapter is devoted to revival, resuscitation and resurrection - the right of passage - and it examines whether resuscitation should be carried out automatically whenever death threatens or whether, in certain situations, the obligation to resucitate is suspended. It questions whether the patient's or the family's wishes or beliefs enable or compel the modification of this obligation in any way, and whether there is a distinct obligation to respect, elicit, or even to make advance directives such as a living will. There are no simple answers. While biological age may predispose to illness and disease, chronological age can predispose to well-intentioned medical neglect. Restricting the resuscitation of the elderly is neither an isolated nor a simple decision and it should be considered objectively in detail.

I recommmend this book to all decision-makers including health professionals and health service planners who have responsibility for the care of the elderly. I need hardly remind readers that maybe growing old is a question of mind over matter - if you don't mind, it doesn't matter - and it should be remembered that everybody is in a queue to grow old one day. Care of the elderly should concern everyone.

BASHIR QURESHI, FRCGP GP in Hounslow, London and author of

Transcultural Medicine

\section{Ethics and Psychiatry: toward Professional Definition}

Allen R Dyer, 176 pages, Washington, USA, £35, American Psychiatric Press Inc, 1988.
Dr Dyer asserts that medical practice has largely become divorced from its ethical traditions so that it is now possible to view medicine as technology and physicians as merely technicians, This development has led to an uncoupling of ethics and expertise, thought from action, such that much discussion of issues in medical ethics fails to take sufficient account of the ongoing relationship between doctor and patient. This is particularly relevant in psychiatry. The author explores this view in a series of essays considering the Hippocratic tradition, ethical theories, confidentiality, informed consent and the place of virtue and character in ethics. Dr Dyer observes that debates in medical ethics often take the Cartesian epistemological outlook for granted and in relation to this he includes a critique of Szasz's approach to mental illness.

The quality of the various essays is somewhat uneven and the extent of coverage of certain topics appears unbalanced. British readers will find the extensive discussion on the ethics of professional advertising of limited relevance. While the goal of idealism and the place of virtue and character in professional ethics occupy complete chapters the chapter on confidentiality could usefully have been expanded and the discussion of ethical aspects of involuntary admission to hospital is extremely brief. There is a helpful outline of various theories of ethics although more practical examples would enhance the reader's grasp of the methods in relation to psychiatry. Dr Dyer emphasises that in his view, the concept of the person should be central to discussions of treatment rather than ethics debated in a manner detached from the person. Informed consent, autonomy and paternalism are explored in more detail. Dr Dyer laments the fact that whereas paternalism might once have been seen as a manifestation of the physician's responsibility it is now largely seen as a measure of the profession's control over patients. He makes a case for the principles of autonomy and paternalism not being mutually exclusive attitudes in the setting of an appropriate doctor-patient relationship. Another useful point made in this chapter concerns the recognition of the dimension of time in the decision-making process. Informed consent in psychiatry is often an ongoing process and there is a certain artificiality in considering it at one particular moment in a legalistic framework.

The book is well presented although 